\title{
Research on Process of Inter-organizational Synergistic Knowledge Creation
}

\author{
Meng Xiao, Zhang Qingpu \\ School of Management, Harbin Institute of Technology, 150001, China
}

\begin{abstract}
The inter-organizational scientific collaboration aimed at knowledge creation involves variety of scientific institutions. The process of synergistic knowledge creation can be viewed as a mode of creating knowledge along with developing partner relationships of synergies. This process which consists of four sequential phrases characterized with different knowledge communications or interactions has been analysed. Furthermore, Synchronically with the knowledge creation process, the evolution of synergistic partner relationships is also explained according to the four stages. Three factors influencing such evolution process are identified at last.
\end{abstract}

Index Terms - knowledge creation, synergistic, interorganizational, process

\section{Introduction}

Breakthroughs in science and technology play an important role in economic development and social progress. With the gradual refinement of division within science research, multiple-organizational collaboration plays an increasingly important role by improving scientific knowledge production, therefore, this type of collaborations have received multi-faceted support, range from science and technology policies to grant-founding initiatives and subsidization.

Many literatures have focused upon synergies and synergistic effects of collaborations. Synergy can be defined as positive emergent capabilities (Nevo and Wade, 2010). A partnership creates synergy by combining the perspectives, knowledge, and skills of diverse partners in a way that enables the partnership to (1) think in new and better ways about how it can achieve its goals; (2) plan more comprehensive, integrated programs; and (3) strengthen its relationship to the broader community. When partners create synergy, they create something new and valuable - a whole that is greater than the sum of its parts (Weiss, Anderson and Lasker, 2002). Synergy mechanism is viewed as a kind of paradigm which emphasizes the system as a whole and system elements. Interactions between elements inside the system, between system and its internal elements, between system and other systems of the environment are all paid great attentions, therefore synergy is a kind of "relationship science" (Corning, 1998).

This article seeks to extend our understandings about the process of common goals via communications and interactions in four sequential phrases, which promote the synergy step by step synergistic knowledge creation in the scientific collaboration background. Synergistic knowledge creation is a creation mode by which universities and other scientific organizations not only create new scientific knowledge, but also develop relationships of synergy, these two goals can be achieved synchronously. Organizations could achieve

\section{Inter-organizatonal Collaboration}

Scientific complicated project calls for appropriate mix and match of the related fields of knowledge. In most cases, university and other scientific organizations are unlikely to solve complex scientific problems on their own, thus, interorganizational cooperation has become an indispensable form of knowledge production.

Inter-organizational scientific collaboration can be defined as follows: several research institutions (universities, research institutes, etc.) work together on a complex scientific project, characterized by resources sharing and knowledge pooling across organizational boundaries. In addition, the division of the project is according to participants' knowledge domains and research advantage, the relationship between participants is not hierarchical, but horizontal and parallel.

\section{Knowledge Creation in Inter-organizational Collaboration}

Sonnenwald (2007) suggested that scientific collaboration involves four stages - foundation, formulation, sustainment and conclusion. Relationships, communications, trusts and familiarities between participants are varying as the collaboration continues. More importantly, in order to accomplish knowledge creation which is the common goal of the project, knowledge exchange and interactions take distinct forms in the four phrases of sequence. Making knowledge area complementary, building knowledge networks, developing common knowledge, and creating new knowledge are identified as the sequential steps of knowledge creation in inter-organizational collaboration. (Figure 1) .

\section{A. Foundation and knowledge complementarity}

Foundation can be called pre-history stage, which includes knowledge, norms, relationships, and policies that exist before the collaboration is formulated (Sonnenwald, 2007). Research skills, geographical closeness, and collaboration experience are all taken into account for selecting appropriate partners. However, the most important objective standard to choose a partner is knowledge complementarity, which makes sure that one organization can acquire knowledge needed from partner organizations, and participants can meet the requirement of the scientific project by pooling their knowledge. 


\section{B. Formulation and knowledge network}

Complex research project is usually divided into several subprojects. Each subproject which is undertaken by one or more organizations formed a task-specific knowledge network (Hansen, 2002). If a participant commit into two or more subprojects at the same time, they occupy a position of structural hole linking different task-specific networks. Besides work-oriented knowledge networks, interpersonal communications also help to extend or sustain the relationships between organizations. Knowledge flows and exchange can be realized through all these formal or informal ties.

\section{Sustainment and common knowledge}

Research field, language system, organizational culture and working methods differentiate one organization from others. As a result, efficiency of knowledge exchange and understandings across organizations may be hard to improve. It may take several months or years for all the participants to adapt themselves to the interactions or the network practices. During this long term, common knowledge can be accumulated to work as an effective tool which can improve knowledge communications and interactions. There are two connotations about common knowledge, the knowledge shared and the awareness that the other knows (Cramton,2001). Owning to common knowledge, scientific knowledge across domains could be understood properly, with little distortion or loss.

\section{Conclusion and new knowledge}

At this time, all participants have accumulated a number of new knowledge and new research skills, but have not yet reached the ultimate goal, they also need to complete the "the last mile", especially how to make their research results compatible with others'. Negotiations and sharing understandings are necessary for dealing with the result conflicts. Furthermore, when writing up results in papers, the agreement of signatures in academic papers depends much on the sense of fairness of contributors affiliated different organizations.

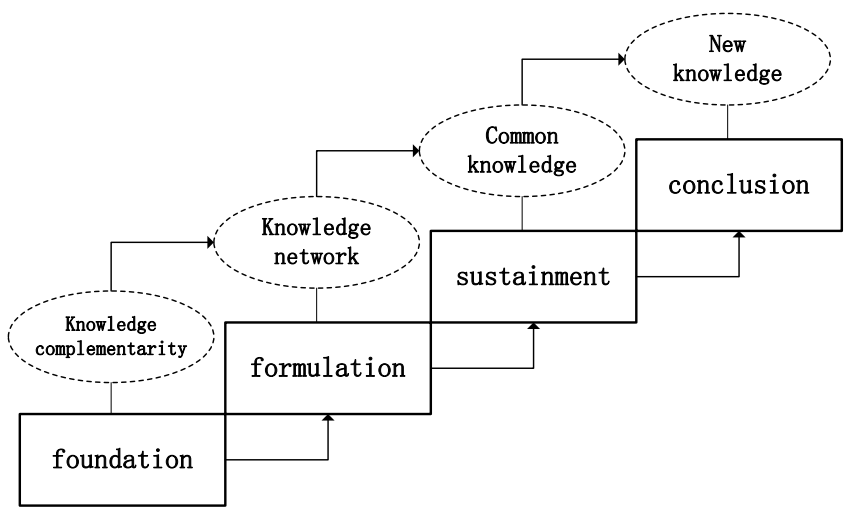

Figure 1 process of inter-organizational knowledge creation

\section{The Evolution of Inter-organizational Synergistic Knowledge Creation Process}

Corresponding with the four stages of knowledge interactions, synergistic knowledge creation is simultaneously realized in four steps: compatible interests, coordination mechanisms, synergistic interactions and cooperative relationship, as illustrated in figure 2.

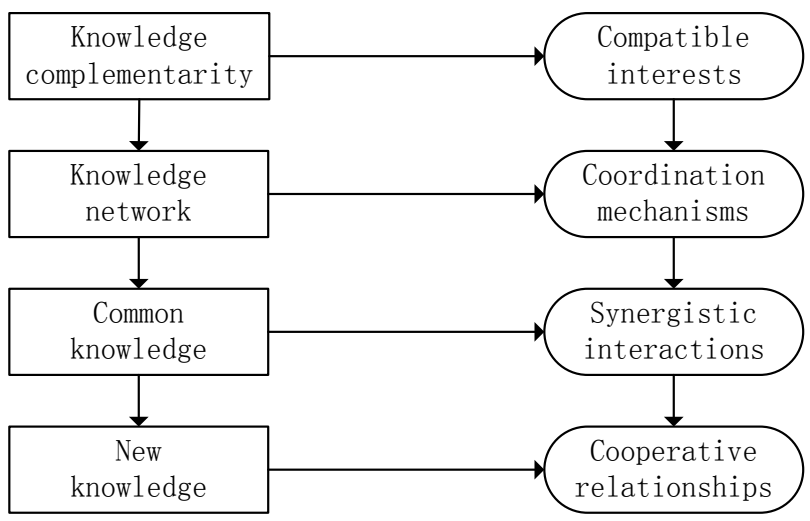

Figure 2 The process of inter-organizational synergistic knowledge creation

\section{A. Compatible interests}

As mentioned earlier, inter-organizational collaboration is based on complementary scientific knowledge. Representatives of organizations involved in research project are usually one or several research teams, their research interests, knowledge domains, work styles have been shaped and sustained in a long run of scientific practices, and are lack of flexibility to meet with other teams automatically. Nevertheless, common goals of the scientific project and communications can help unify the variety of research interests and directions. During the stage of foundation, all the research partners should aware of the meaning of a collaboration, that some knowledge domain are vital to the project, and some may be peripheral. When selecting partners, teams with knowledge critical to the project initiate the communications with other teams who dedicated in researches not so important. After a period of mutual observations and assessment, not only knowledge complementarity can be achieved, but the extent to which scientific interests are compatible with each other can be advanced. A collaboration will not be approved by the potential participants until they make a basic consensus about research goals, paths, work divisions and so on.

\section{B. Coordination mechanisms}

After establishment of the work division, knowledge network begin to emerge accordingly. There are many factors that may affect the quality of seemingly well-organized cooperation. Firstly, inter-organizational communications, especially communications across geographic distance take much time and economic costs, such as video conference, travel, etc., which would lessen willingness and enthusiasm of communication between dispersed organizations. In this way, 
some problems which need to be discussed immediately may be shelved, concealed, delayed, and research progress and quality will be affected consequently. Secondly, as mentioned earlier, only part of an organization, maybe one research group or a laboratory involved in the inter-organizational collaboration. While undertaking research tasks, they also need to accomplish the work designated by their own institutions, and therefore unintentionally neglect the project work, or depend on the support of partner organizations excessively, even do opportunistic deeds.

Thus, in order to avoid these negative things, collaborators can adopt coordination mechanisms as a regulatory framework for future communications and interactions. Coordination mechanisms include formal or informal agreement, such as how to manage the conflict among participants; how to determine the order of signatures when writing articles; and the frequency of project meetings, etc. In addition, the dynamic coordination mechanism is also essential in research projects. Committee of experts, chief scientist and administrative secretaries, are jointly responsible for solving the problems whenever and wherever needed.

\section{Synergistic interactions}

Participants' behaviours are continuously shaped by the prior interactions with their partners, not merely rely on their own capabilities and resources. Both partners can receive and save information from each other, some information can influence their expectations and choices and adjust the patterns and specifics of their behaviours during the multiple knowledge interactions. Information often comprises weakness, advantages, attitudes, preferences, routines and so on. For example, different organizations which used to different language systems couldn't catch on and understand expertise from partners at the beginning, then they made some suggestions about language using to attenuate this obstacle. Suggestions, feedbacks and the like can formulate and develop common knowledge which works to coordinate future interactions. There is a mutual enhance between common knowledge and interactions, the more common knowledge, the more synergies can be found in interactions; the more interactions, the more common knowledge can be accumulated.

\section{Cooperative relationships}

Repeated interactions and mutual familiarities are conductive to the emergence of relationship governance based on social emotions, trust and norms (Gulati, 2000). Frequent and effective interactions can lead to higher magnitude of partner relationships, called cooperative relationships. Cooperative relationships are not well-defined, but there is some agreement in the literature which describe cooperative relationships as working together toward common goals and sharing (Golicic, Foggin and Mentzer, 2003). When times, locations, patterns, and goals could quickly converge to consensus among partners, without tedious process of negotiation, familiarities and trust have brought partners to a new collaborative situation, they can enjoy the cooperative relationships rather than endure the inadaptation of working with others.

\section{The Affecting Factors of Inter-organizational Synergistic Knowledge Creation Process}

The process of synergistic knowledge creation might be affected by the presence of some conditions. Hence, this section describes these affecting factors briefly, as illustrated in figure 3.

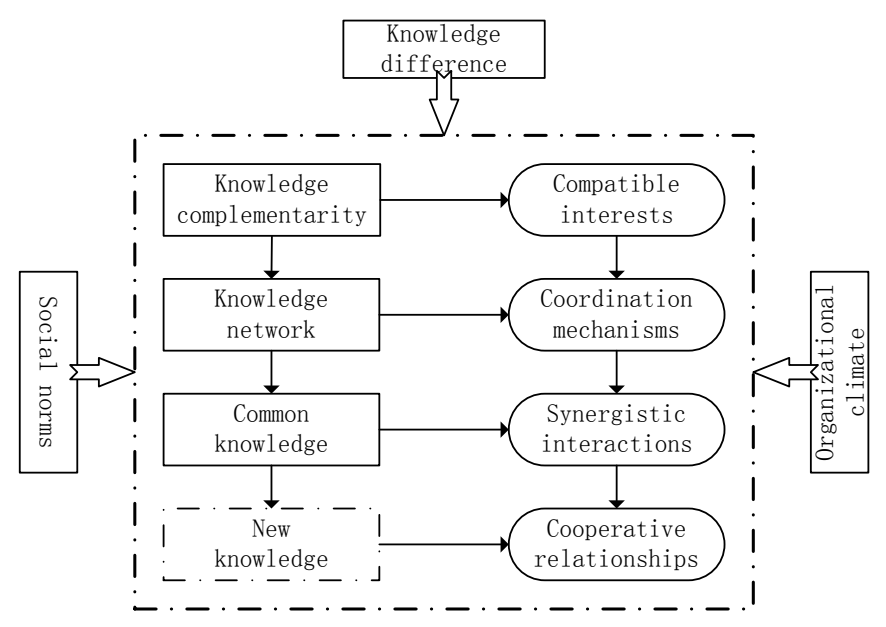

Figure 3 The affecting factors of the process of synergistic knowledge creation

\section{A. Knowledge differences}

In some cases, organizational boundary span is accompanied by inter-discipline, such as geologists and meteorologists, mathematicians and physicists, psychologists and linguists. In other cases, inter-organization collaboration happens within the same discipline, but across different research domains, such as mechanics of materials and mechanics of vibration. In short, knowledge differences always exist among organizations engaged in scientific project. Knowledge differences could influence the quantities and qualities of knowledge co-created. When the degree of knowledge overlaps is lower, the communications are likely to become difficult and disorderly. The communicators of both sides should increase patience and nurture effective means gradually. On the other hand, large differences of knowledge represent the definite relationship of knowledge complementarity between partners, this complementary relationship can arouse more interests and efforts to communicate with each other, leading to more creative inspirations key to knowledge creation. Wagner has argued that collaborators with intellectual boundaries can be assumed to have different points of view and different experiences. As a result, they may be more likely to challenge or perhaps complement the outlook and capabilities of others.

\section{B. Organizational climate}

Organizational climate refers to common practice, shared beliefs, and value systems that an organization follows (Janz, 
Wehterbe, Colquitt, \& Noe, 1997). Organizational climate plays an essential role in shaping employees' behaviours and influencing their perception of knowledge management (Chen \& Lin, 2004). Organizations dedicated to science have something similar to each other, such as encouraging innovation, team spirit, pursuit for truth, which are parts of organizational climate. These similarities provide the interorganizational scientific collaboration with much more harmonies, which can increase synergies between partners. On the other hand, different organizations necessarily have something different in organizational climate, which could cause the lower extent to which partners approve of behaviours of others. For example, a research team from an organization has very rich research achievements, but its scientists are not good at expression or propaganda, their counterpart of the other organization is just the opposite style, as a result, there are lots of complaints and discontents during the course of their collaboration.

\section{Social norms}

Elster viewed social norms as a kind of informal rules, a kind of stable expectations and common belief, that when you are expecting what others would do, and others are expecting what you would do, these expectations become common faith, viewed as social norms or culture. Social norms are noneconomic constraints, and mainly manifested as social exclusion, mockery, criticism and d reputation damage. People have preferences for social norms so that they tend to seek social identity which has nothing to do with money ( Lindbeck A., Snower D. J., 1988; Hollander H., 1990). In science communities or academia, there are more specific social norms which can regulate the behaviors of science practitioners. For instance, scientists value the academic reputations so much, that they always work on researches with their honesty and integrity, and contempt academic misconduct, such as fabricating data or occupying results that not belong to them. Fundamental trust and respect due to social norms of academia can accelerate the coordination among partners affiliate distinct organizations.

\section{Conclusion}

The refinement of fields of science leads to interorganizational collaborations for complex projects. Knowledge creation is the ultimate and common goal of scientific collaborations. Although the division of scientific tasks and networks are conductive to knowledge creation, they are still not enough for the synergies which can be achieved in the process of knowledge creation. We identified four stages of scientific collaboration, where knowledge creation is accomplished through a sequence of knowledge communications or interactions. Furthermore, the synergies underlie such process could be achieved synchronously.

\section{References}

[1] Saggi Nevo, Michael R. Wade, "The formation and value of IT-enabled resources: antecedents and consequences of synergistic relationships." MIS Quarterly, 2010, 34(1), pp. 163-183.

[2] Elisa S. Weiss, Rebecca Miller Anderson, Roz D. Lasker, "Making the most of collaboration: Exploring the relationship between partnership synergy and partnership functioning." Health Education\&Behavior, 2002, 29(6), pp. 683-698.

[3] Corning P A. "The synergism hypothesis: on the concept of synergy and its role in evolution of complex systems". Journal of Social and Evolutionary Systems, 1998, 21(2), pp. 133-172.

[4] Diane H. Sonnenwald. "Scientific collaboration: a synthesis of challenges strategies." Blaise Cronin. Annual Review of Information Science and Technology. Medford, NJ: Information Today, 2007, pp. 643-681.

[5] Morten T. Hansen. "Knowledge networks: explaining effective knowledge sharing in multiunit companies." Organization Science, 2002, 13(3), pp. 232-248

[6] Catherine Durnell Cramton. The mutual knowledge problem and its consequences for dispersed collaboration. Organization Science, 2001, 12(3), pp. 346-371

[7] Gulati, Ranjay. "Strategic networks." Strategic Management Journal. 2000, (211), pp. 781-790.

[8] Susan L. Golicic, James H. Foggin, John T. Mentzer, "Relationship magnitude and its role in interorganizational relationship structure." Journal of business logistics, 2003, 24(1), pp. 57-74.

[9] Caroline S. Wagner. "Six case studies of international collaboration in science." Scientometrics, 2005, 62(1), pp. 3-26.

[10] Janz, B. D., Wehterbe, J. C., Colquitt, J. A., \& Noe, R. A. . "Knowledge worker team effectiveness: The role of autonomy interdependence, team development, and contextual support variables." Personnel Psychology, 1997, 50(4), pp. 877-904.

[11] Chen, C., \& Lin, B.. "The effects of environment, knowledge attribute, organizational climate, and firm characteristics on knowledge sourcing decisions." R\&D Management, 2004, 34(2), pp. 137-146.

[12] Elster J.. "Social Norms and Economic Theory." Journal of Economic Perspective, 1989, 3: pp. 99-117.

[13] Lindbeck A., Snower D. J. Cooperation, Harassment, and Involuntary Unemployment: An Insider-outsider Approach, American Economic Review. American Economic Association, 1988, 78(1), pp. 167-188.

[14] Hollander H.. "A Social Exchange Approach to Voluntary Cooperation." The American Economic Review, 1990, 80(5), pp. 1571167. 